\title{
O histórico da escola pública moderna, sua configuração contemporânea e função social
}

\author{
The history of the modern public school, its contemporary \\ configuration and social function
}

\section{El histórico de escuela pública moderna, su configuración contemporánea y función social}

\author{
Lilian Giacomini Cruz Zucchini ${ }^{1}$ \\ Universidade Estadual de Mato Grosso do Sul de luinhema, Professora e Coordenadora nos \\ Cursos de Licenciatura e Bacharelado em Ciências Biológicas

\section{Marcela de Moraes Agudo ${ }^{2}$} \\ Universidade Federal de Itajubá, Professora Adjunta no Curso de Ciências Biológicas \\ Licenciatura
}

Resumo: A educação pública não é uma invenção dos tempos modernos, mas a escola tal como a concebemos hoje - universal, laica, gratuita e obrigatória - é uma instituição recente, tendo seus princípios discutidos e/ou redefinidos inicialmente durante o período da Revolução Francesa, consolidando-se posteriormente, no final do século XIX e início do século XX, quando alguns países reorganizaram e implantaram seus sistemas nacionais de educação. A partir da noção histórica do desenvolvimento e da constituição da escola pública que temos atualmente, refletimos sobre a concepção de escola pública que compreendemos, ou seja, entendendo o significado do "público" que caracteriza a escola como tal e de que modo se desenvolveu historicamente. A escola, tal qual a conhecemos, é resultado de um acerto de contas: com o poder absolutista do Estado; com a ideologia dominante centrada na visão metafísica do mundo; e, finalmente, com a concepção da desigualdade humana como algo determinado pela natureza. Mesmo que, em diversos momentos, movimentos de resistência tenham reivindicado e reivindiquem o desenvolvimento de uma escola pública popular de fato, este enfrentamento

Doutora em Educação para a Ciência pela Universidade Estadual Paulista "Júlio de Mesquita Filho" de Bauru, com período de estágio (Doutorado Sanduíche) na Universidade de Santiago de Compostela, Espanha; Especialista em Gerenciamento Ambiental pela Escola Superior de Agricultura Luiz de Queiroz da Universidade de São Paulo.

2 Doutora e Mestre em Educação para a Ciência pela Universidade Estadual Paulista "Júlio de Mesquita Filho" de Bauru (Bolsista Capes - Proex e FAPESP). 
ainda se faz necessário para a constituição de uma escola pública, laica, gratuita, de qualidade socialmente referenciada e desinteressada. Destacamos, a partir de Gramsci, a importância de um movimento intelectual e popular que difunda novas concepções de mundo capazes de desenvolver a consciência civil da população e de produzir novos comportamentos para que ela não se submeta à direção do Estado capitalista.

Palavras-chave: Escola pública. Origem. Histórico. Função social.

Abstract: Public education is not an invention of modern times, but the school as we conceive it today - universal, secular, unpaid and obligatory - is a recent institution, with its principles discussed and/or redefined initially during the period of the French Revolution, consolidating later in the late nineteenth and early twentieth centuries when some countries reorganized and implemented their national education systems. From the historical notion of the development and constitution of the public school that we currently have, we think about the conception of public school that we understand. That is, understanding the meaning of the "public" that characterizes the school as such and how it has developed historically. The school, as we know it, is the result of a settling of accounts: with the absolute power of the State; with the dominant ideology centered on the metaphysical view of the world; and finally, with the conception of human inequality as something determined by nature. Even though, at various moments, resistance movements have claimed and claim the development of a popular public school in fact, this confrontation is still necessary to create a public, secular, free, obligatory, high quality and disinterested school. From Gramsci we emphasize the importance of an intellectual movement that diffuses new world conceptions capable of raising the civil conscience of the population and producing new behaviors that not submit to the direction of the capitalist State.

Keywords: Public school. Origin. Historic. Social function.

Resumen: La educación pública no es una invención de los tiempos modernos, pero la escuela tal como la concebimos hoy - universal, laica, gratuita y obligatoria - es una institución reciente, teniendo sus principios discutidos y/o redefinidos inicialmente durante el período de la Revolución Francesa, consolidando posteriormente, a finales del siglo XIX y principios del siglo XX cuando algunos países reorganizaron y implantaron sus sistemas nacionales de educación. A partir de la noción histórica del desarrollo y de la constitución de 
la escuela pública que tenemos actualmente, pensamos sobre la concepción de la escuela pública que comprendemos. Es decir, entendiendo el significado del "público" que caracteriza a la escuela como tal y de qué modo se desarrolló históricamente. La escuela, tal como la conocemos, es resultado de un acierto de cuentas: con el poder absolutista del Estado; con la ideología dominante centrada en la visión metafísica del mundo; y finalmente, con la concepción de la desigualdad humana como algo determinado por la naturaleza. Aunque en diversos momentos, movimientos de resistencia reivindicaron y reivindican el desarrollo de una escuela pública popular de hecho, este enfrentamiento aún se hace necesario para la constitución de una escuela pública, laica, gratuita, obligatoria, de alta calidad y desinteresada. Destacamos, a partir de Gramsci, la importancia de un movimiento intelectual que difunda nuevas concepciones de mundo capaces de elevar la conciencia civil de la población y de producir nuevos comportamientos para que ella no se someta a la dirección del Estado capitalista.

Palabras clave: Escuela pública. Origen. Histórico. Función social.

\section{INTRODUÇÃO}

Buscamos analisar a escola pública no Brasil, compreendendo essa instituição social como uma construção histórica, com diversos desafios, contradições e possibilidades ocorridos ao longo do tempo. A partir da compreensão histórica, no movimento dialético da realidade concreta, consideramos que é possível refletir acerca dos enfrentamentos necessários para construirmos coletivamente a escola pública que queremos.

Assim, neste ensaio teórico, buscamos entender a origem da escola pública e a historicidade desta instituição social, que foi estudada e analisada por Enguita (1989), Lopes (2008), Lombardi, Saviani e Nascimento (2005) e Saviani (2007, 2008). Esses autores proporcionaram uma discussão crítica em relação ao tema da escola pública, tratando de sua história, dos fatos de sua organização, muitas vezes velados, em razão da sua constituição insistentemente estabelecida por meio de disputas de poderes; e como 
essas disputas constituíram e constituem a escola pública "interessada" da contemporaneidade, Gramsci (201 1, p. 33) discute:

\begin{abstract}
A tendência atual é a de abolir qualquer tipo de escola "desinteressada" (não imediatamente interessada) e "formativa", ou de conservar apenas um seu reduzido exemplar, destinado a uma pequena elite de senhores e de mulheres que não devem pensar em preparar-se para um futuro profissional, bem como a de difundir cada vez mais as escolas profissionais especializadas, nas quais o destino do aluno e sua futura atividade são predeterminados.
\end{abstract}

Portanto, a partir de alguns pontos que consideramos principais da história da constituição da escola pública, buscamos discutir sua origem, o significado de ser pública e algumas perspectivas para a escola pública na contemporaneidade, bem como as contradições que surgiram nesse processo. Para a discussão das alternativas e possibilidades que vislumbramos, tendo em vista a superação da organização da escola pública que temos, autores como Ribeiro (2001), Saviani (2005) e Gramsci (2011) indicaram algumas alternativas para a superação da atual organização da escola pública e do trabalho pedagógico (ALVES, 2004).

Nesse sentido, discutiremos a origem da escola pública, algumas perspectivas no Brasil e o necessário enfrentamento e superação da sua atual organização, tendo como foco a qualidade socialmente referenciada, popular, que atenda aos interesses da população, proporcionando uma formação integral dos estudantes, considerando a humanização plena dos sujeitos.

\title{
2 ORIGEM DA ESCOLA PÚBLICA
}

A educação pública não é uma invenção dos tempos modernos, mas a escola como a concebemos hoje - universal, laica, gratuita e obrigatória - se constitui uma instituição recente, tendo seus princípios discutidos e/ ou redefinidos inicialmente durante o período da Revolução Francesa, 
consolidando-se posteriormente, no final do século XIX e início do século XX, quando alguns países mais desenvolvidos reorganizaram e implantaram seus sistemas nacionais de educação (LEONEL, 1994).

De acordo com Souza, Ferreira e Barros (2009), é importante lembrarmos que, no decorrer do Período Feudal, a educação institucionalizada estava atrelada à Igreja e voltava-se à formação do clero e dos membros de uma classe privilegiada. As crianças provenientes da nobreza eram educadas em seus lares por preceptores contratados para tal fim. Assim, esse período se destacou por uma educação elitizada, à qual poucos tinham acesso.

Para a compreensão da origem da escola pública moderna, faz-se necessário recorrermos a alguns momentos da história, investigando o caminho percorrido pela educação no processo de formação social do ser humano na modernidade, até atingir o formato no qual a burguesia o consolidou por meio da escola pública.

Segundo Leonel (1994), é na França, mais do que em qualquer outro país, que a discussão da escola pública toma a forma de um grande debate porque se faz no interior da luta de classes, em uma fase difícil de consolidação da república francesa. Lembremos que esse processo teve início ainda na segunda metade do século XVIII, culminando na Revolução Francesa, que é o nome dado ao conjunto de acontecimentos que, entre 1789 e 1799, alteraram o quadro político e social da França.

Sobre esse período, Lopes (2008) nos traz grande contribuição, elucidando a complexidade desse momento histórico:

Podemos compreender o movimento revolucionário de 1789 analisando a oposição existente entre as estruturas e instituições do Antigo Regime e o movimento econômico e social dirigido pela burguesia, que trazia não só novos meios de produção, como também uma nova concepção de mundo. No entanto, essa Revolução não foi fruto do trabalho de apenas uma classe. Ao contrário, ela é a eclosão de uma longa e complexa luta de classes e o resultado de alianças de classes, envolvendo todo o povo francês. (LOPES, 2008, p. 21). 
Como resultado de todas as lutas e alianças de classes travadas durante o período da Revolução Francesa, surge um novo modo de vida, substituindo definitivamente o sistema de produção da vida feudal pelo capitalista, além de reduzir consideravelmente o poder da monarquia, da nobreza e do clero.

A Revolução Francesa foi, em verdade, uma revolução burguesa. No entanto, uma revolução burguesa e democrática. Burguesa, porque foi liderada pela burguesia, apesar de esta ser bastante heterogênea e apresentar atuações diversas, e democrática no sentido de que contou com o apoio das camadas populares, inclusive a grande população rural, procurando uma conciliação, que então se mostrou muito mais favorável aos interesses burgueses que aos camponeses.

Com todas essas mudanças, a instrução vigente também deveria ser substituída por uma nova maneira de instruir a população que pudesse, principalmente, ser desfrutada por todos aqueles que lutaram por tais mudanças na organização social, econômica, política e cultural daquele momento histórico. Assim, com o objetivo de consolidar seu projeto hegemônico, a burguesia se apropriou da ideia de escola pública, a fim de redefini-la e convertê-la em um instrumento de disseminação de sua concepção de mundo.

Nesse momento, conforme discutem Souza, Ferreira e Barros (2009), ao tomar o poder, a burguesia "idealmente" exigiu que, com outros privilégios exclusivos da nobreza feudal, a educação fosse voltada para toda a população, passando a ser um direito dessa maioria, deixando de ser apenas privilégio de uma classe. Assim, naquele contexto e momento histórico, a educação moderna deixou de ser "privilégio" para se tornar um "direito".

Com a abolição da velha ordem econômica, a burguesia tratou de abolir também a moral a ela subjacente, o que significa que:

- Racionalismo e o Iluminismo haviam preparado o caminho para a nova moral, que tinha por bases uma concepção individualista de vida, uma satisfação garantida mediante a obtenção de lucros monetários imediatos, a produção sem limites etc. A superação do feudalismo trouxera uma nova concepção de propriedade. Livre, individual, total, permitindo seu uso e abuso, tendo 
como limite apenas a propriedade alheia, é a concepção burguesa da propriedade. (LOPES, 2008, p. 82).

A implantação e a consolidação dessa nova moral burguesa dependiam também do sucesso da nova ordem econômica. Nesse sentido, a instrução passou a cumprir um papel de destaque: agir rapidamente sobre o aperfeiçoamento do corpo político e sobre a prosperidade geral.

Em outras palavras, quando a burguesia revolucionária se firma definitivamente no poder como classe dominante e dirigente da sociedade, a educação é instituída como um dever, afinal, o homem dessa sociedade precisava ser educado para se adaptar ao novo modo de produção capitalista e também a uma nova moral burguesa (SOUZA; FERREIRA; BARROS, 2009).

Para melhor compreensão desse "novo" olhar para a educação e da importância que ela assume para a consolidação da hegemonia burguesa, é importante salientarmos que em um dado momento da história, essa classe passa de revolucionária a reacionária.

De acordo com Souza, Ferreira e Barros (2009), após sua sedimentação no poder como classe dominante, a burguesia começou a enfrentar várias crises e comoções sociais, provenientes das contradições instituídas pelo modo de produção que se consolidava. Além disso, a exploração da classe proletária pela maximização do lucro começou a gerar uma crise de grandes proporções. A possibilidade de haver outra revolução era muito grande.

No entanto, tendo já vencido uma revolução, a burguesia conhecia muito bem as estratégias de luta usadas para conter a revolta da classe proletária. Ou seja, ela sabia como fazer a "contra-revolução", e esta não seria mais pela força nem pelas guerras, mas por meio de um novo instrumento, mais eficaz e menos devastador para ambos os lados, ou seja, por meio da educação. E foi nesse período conturbado do início do século XIX, período de transição e de conflitos sociais da expansão mundial do comércio, que o surgimento da escola pública se tornou algo inadiável (SOUZA; FERREIRA; BARROS, 2009). 
A escola pública, organizada de acordo com os princípios burgueses, viria assegurar e defender os interesses dessa classe dominante diante das possíveis crises do capital:

Ora, se os interesses burgueses têm que passar pelo sufrágio universal e a sociedade se encontra dividida em classes antagônicas, a escola pública não pode mais ser adiada. É preciso educar o novo soberano, transformando o sujeito, submetido aos antigos poderes, em cidadão defensor da pátria amada; substituir seus "deveres para com Deus" pelos seus "deveres para com o Estado". (LEONEL, 1994, p. 184-185).

Por último, é necessário retomarmos que um dos objetivos principais daquela burguesia inicialmente revolucionária era atingir a "igualdade" de direitos às diferentes classes, isto é, preconizava que viver naquele novo modelo de sociedade - protegido e/ou punido pela mesma legislação - requeriria o firmamento de uma igualdade quanto ao acesso às oportunidades de formação.

Segundo Boto (2005), no território pedagógico, o que a Revolução Francesa fizera, no sentido da materialidade objetiva, deveria se firmar subjetivamente no coração e nas almas de um povo a ser instruído.

A escola desenhada pelos revolucionários franceses era tida por universal e única para todos, de maneira que os mais talentosos pudessem "naturalmente" expressar o seu mérito e o seu destaque. Surge como bandeira de luta da escola moderna de Estado o sonho republicano por um sistema de ensino público, gratuito, laico, universal, único e obrigatório. Seria universal por pretender colocar na mesma classe todas as crianças, todos os jovens meninos e meninas, ricos e pobres, loiros e morenos, católicos, protestantes, judeus ou muçulmanos, habitantes das cidades ou dos campos. Supunha-se único porque o ensino ministrado, no conjunto, deveria ser o mesmo quanto a seus conteúdos e a seus métodos, para todos os estudantes, independentemente de quaisquer identidades e pertenças comunitárias por eles abraçadas. (BOTO, 2005, p. 785). 


\section{0 SIGNIFICADO DE SER “PÚBLICA” A ESCOLA PÚBLICA}

A partir da noção histórica do desenvolvimento e da constituição da escola pública que temos atualmente, é necessário pensarmos também sobre a concepção de escola pública que compreendemos. Ou seja, entender o significado do "público" que caracteriza a escola como tal e de que modo se desenvolveu historicamente.

Saviani (2005) discute sobre três acepções acerca da adjetivação do "público" caracterizando a escola. A primeira refere-se ao público considerando o comum, de todos, em contraposição ao privado e individual; a segunda está relacionada à população, no sentido de ser popular em contraposição ao que é das elites; e a terceira referindo-se como público ao que se relaciona com o Estado como instituição que deveria cuidar dos interesses coletivos.

A terceira acepção é a que prevalece no século XX. Sanfelice (2005, p. 91) atenta também para a necessidade de diferenciação entre os termos público e estatal, comumente utilizados e divulgados como sinônimos, chegando à conclusão de que "o Estado ou o que é estatal não é público ou do interesse público, mas tende ao favorecimento do interesse privado ou aos interesses do próprio Estado, com a sua autonomia relativa."

Sanfelice (2005) discute que a educação popular precisa ser realizada pela escola pública, fazendo do Estado o educador do povo, com base em Marx e Engels, que discutiram que a educação popular a cargo desse Estado burguês é inadmissível. Com isso, podemos perceber que a escola pública contemporânea não é popular, pois o Estado é o educador do povo, então temos a escola estatal do Estado educador do povo.

Assim, nas disputas de poder, o Estado atende aos interesses da minoria dominante do País, sobrepõe-se ao público, chamando de público o que é estatal. Sanfelice (2005) considera que a lógica marxiana propõe a conversão do estatal em público quando afirma que é o povo que deve educar o Estado. 
A partir das diferentes acepções acerca do conceito de escola pública que Saviani (2005) desenvolve, mostra-se importante discutirmos alguns pontos. A escola pública no sentido de ensino coletivo tem como principal forma o método simultâneo, de oposição ao ensino individual, encarregado pelos preceptores. A escola pública como ensino coletivo está relacionada ao período do fim da Idade Média, com o objetivo de alfabetizar a população.

A escola pública no sentido de popular visa à educação de toda a população, por meio da organização dos Sistemas Nacionais de Ensino, a fim de garantir o ler, o escrever e o contar. A partir do século XIX, no contexto da Revolução Francesa, é que essa acepção se consolida, referindo ao ensino elementar. A escola pública como estatal é aquela organizada e mantida pelo Estado, abrangendo todos os graus e ramos de ensino, que deveria garantir condições materiais e pedagógicas para seu funcionamento adequado. Esse significado prevaleceu no século XX, no contexto do Estado liberal em direção ao Estado de bem-estar social (SAVIANI, 2005).

Porém, no final do século XX e início do século XXI, o Estado neoliberal traz as ideias de terceiro setor e de "público-não-estatal", como levanta Saviani (2005). Nesse sentido, a escola pública e a educação por ela fornecida é dever do Estado e da sociedade, ou seja, é colocada em um setor de serviços que não são exclusivos do Estado. Com isso, como afirma Chaui (2003), a educação passou de direito à serviço prestado e deixou de ser um serviço público e passou a ser considerada um serviço que pode ser privado ou privatizado.

Ou seja, a escola pública deixou de ser uma instituição social, que poderia se "relacionar com o todo da sociedade e com o Estado de maneira conflituosa, dividindo-se internamente entre os que são favoráveis e os que são contrários à maneira como a sociedade de classes e o Estado reforçam a divisão e a exclusão sociais." (CHAUI, 2003, p. 6) e foi definida como organização social.

A escola pública enquanto organização social é regida por ideias administrativas, em que há gestão, planejamento, execução e produto final. Chaui (2003, p. 6) afirma que a instituição "tem a sociedade como seu princípio e sua referência normativa e valorativa, enquanto a organização tem apenas a si mesma como referência, num processo de competição com outras que fixaram 
os mesmos objetivos particulares. "Desse modo, a escola pública contemporânea visa à gestão de suas atividades particulares e pontuais, assumindo o papel de prestadora de serviços e atendendo aos índices de avaliações internacionais.

Com o início da universalização da educação sistematizada e a mudança da escola pública de instituição social para organização social, entramos na problemática dual entre qualidade e quantidade. A expressão de senso comum "a escola pública no meu tempo era boa", que ouvimos nas escolas e em outros espaços sociais, está relacionada à educação escolar até o período anterior à "universalização" do ensino público. As escolas eram pouco numerosas e atendiam somente aos jovens e crianças da pequena fração social rica da população, que não tinham de contribuir para a renda familiar e, portanto, não necessitavam ter empregos.

A qualidade referida pelo termo "boa" na expressão tem relação ao emprego do ensino tradicional, ou seja, conteudista e autoritário. Essa expressão não tem sentido nem no âmbito pedagógico, em que se empregava uma pedagogia tradicional no processo de ensino e de aprendizagem e nem no sentido social, pois a grande maioria da população, proletária, não tinha acesso a esse ensino oferecido. É nesse sentido que vemos como necessário a reflexão sobre as possibilidades de transformações na escola pública.

\section{PERSPECTIUAS DA ESCOLA PÚBLICA NO BRASIL}

De acordo com Frigotto (2011), a escola moderna, tal qual a conhecemos, é resultado de um acerto de contas: com o poder absolutista do Estado; com a ideologia dominante centrada na visão metafísica do mundo; e, finalmente, com a concepção da desigualdade humana como algo determinado pela natureza.

Tal acerto, conforme já sublinhamos, deu à burguesia um papel revolucionário e civilizatório. Entretanto, Marx (201 l) nos mostra que o fato de a burguesia não ter abolido as classes sociais que cindem o gênero humano, estabeleceram-se apenas formalmente a igualdade e a liberdade. 
A escola pública, universal, gratuita e laica constituída como aparelho de hegemonia, teve como objetivo central educar para um consenso que entendesse a sociedade capitalista como uma sociedade de tipo "natural", por ser a que se organiza de acordo com a natureza humana utilitarista, em que cada um lutando pelo interesse próprio, "negociando" no mercado, geraria a prosperidade para todos.

A necessidade, por um processo contínuo, prolongado e renovado, de inculcar esse ideário evidencia que existe resistência ativa e luta contra-hegemônica da classe trabalhadora e seus intelectuais. É nesse sentido que Marx e Engels afirmam que a história humana, até hoje, vem sendo demarcada pela luta de classes. A educação escolar e a sua qualidade estão, pois, organicamente implicadas nessa disputa. (FRIGOTTO, 201 l, p. 80).

Dessa forma, a educação pública vem sendo produzida historicamente nos embates político-sociais a partir da luta em prol de princípios como a laicidade, a gratuidade, a obrigatoriedade e a universalização do acesso, além da ampliação do atendimento e da garantia da qualidade socialmente referenciada. Esses aspectos vinculam-se à criação de condições para a oferta de educação pública, tendo por base a concepção de educação como direito social.

No Brasil, a luta pela democratização da educação tem sido uma bandeira de longa data dos movimentos sociais, inclusive os populares. Podemos identificar em nossa história inúmeros movimentos, gerados pela sociedade, que exigiam, e ainda exigem, a ampliação do atendimento educacional a parcelas cada vez mais amplas da sociedade. $\bigcirc$ Estado, por sua vez, vem atendendo a essas reivindicações de forma muito tímida, longe da universalização esperada (CONFERÊNCIA NACIONAL DE EDUCAÇÃO, 2011 ).

A demanda social por educação pública implica, pois, produzir uma instituição educativa democrática e de qualidade socialmente referenciada, devendo garantir o acesso ao conhecimento e ao patrimônio cultural historicamente produzido pela sociedade. 
Se a educação é uma exigência humana e a escola foi, historicamente, "escolhida" como a instituição social principal responsável para cumprir essa tarefa, qual é a especificidade da escola? Numa perspectiva crítica, que concebe a educação como um processo de instrumentalização dos sujeitos para a prática social transformadora, Saviani (2005) define a escola como: "uma instituição cujo papel consiste na socialização do saber sistematizado". Isso significa afirmar que a especificidade da educação escolar está em promover a consciência dos educandos para a compreensão e a transformação da realidade. Então, o que é próprio da escola é a garantia da transmissão - não mecânica, mas ativa - do saber elaborado pela cultura. (TOZONI-REIS, 2012, p. 6).

Nas diversas instâncias do poder público: União, Estados, Distrito Federal e Municípios, pode-se perceber o esforço em atender às demandas sociais por educação básica, porém de forma focalizada e restritiva. $\bigcirc$ foco ocorreu na ampliação significativa do acesso a apenas um dos segmentos da educação básica: o ensino fundamental, com o atendimento a 32.086.188 estudantes (CONFERÊNCIA NACIONAL DE EDUCAÇÃO, 201 l).

No entanto, mesmo no ensino fundamental, há uma restrição evidente, pois somente às crianças de seis a 14 anos é garantida a oferta obrigatória do ensino fundamental. Sendo assim, parcelas dos jovens e adultos ficam à margem do atendimento no ensino fundamental, bem como parte das crianças de zero a seis anos, demanda da educação infantil, e dos jovens, clientela do ensino médio, tem atendimento ainda insuficiente pelo Estado, o que assume dimensão ainda mais crítica, quando se consideram os enormes desafios para garantir acesso com qualidade à educação superior (CONFERÊNCIA NACIONAL DE EDUCAÇÃO, 2011).

Oliveira (2007) atribui importância significativa à universalização do acesso ao ensino fundamental, posto que essa condição de "universalização" faz com que "as contradições mudem de lugar", passando a se concentrar na expansão das etapas posteriores a este e na qualidade da educação básica, notadamente do ensino fundamental.

Ainda segundo o autor, é importante destacar que, mesmo com um atraso de quase um século em relação aos países centrais, essa expansão das oportunidades de acesso e permanência no sistema escolar para amplas camadas 
da população, de característica mais democratizadora, confronta-se com uma perspectiva política de redução do investimento público em educação, decorrente das opções macroeconômicas do ajuste fiscal e da geração de superávits primários, principalmente quando pensamos na condição de país periférico.

Tal tensão entre um sistema educativo em franca ampliação, por vagas e qualidade, e uma agenda política e econômica conservadora gera um conflito sem precedentes em nossa história educacional. Além do atendimento à demanda por mais educação, debatemo-nos com a tensão entre o direito à educação de qualidade para amplos contingentes da população ou sua negação, o que pode tornar inócua a democratização do acesso, quer seja por sua distribuição diferenciada, quer seja por, e também, relegar a qualidade a nichos de privilégio no interior do sistema educacional. (OLIVEIRA, 2007, p. 666).

Segundo Tozoni-Reis (2012), para a educação pública, as políticas públicas têm mostrado uma face comum: ampliação do atendimento das crianças no ensino fundamental, conforme apresentamos anteriormente, e uma tendência para o "fracasso escolar", considerando que grande parte das crianças do ensino fundamental público, quando terminam esse grau de ensino, apresentam sérias e profundas falhas no desempenho da leitura, escrita e cálculo, principais objetivos do ensino fundamental.

No entanto, ainda segundo a autora, em políticas públicas, a quantidade, expressa pela garantia de vagas para todos nas escolas públicas, é tão importante quanto a qualidade, em especial quando pensamos na democratização do ensino no País. Assim, segundo Tozoni-Reis (2012), é necessário que estejamos atentos ao fato de que, por mais agressivas que tenham sido as políticas públicas de ensino fundamental no que diz respeito à universalização, o conjunto de propostas, ações e medidas educacionais qualitativas necessárias para o ensino fundamental não acompanhou as ações dirigidas aos aspectos quantitativos, e isso não foi "por acaso". Nesse sentido, é importante analisarmos os fatos com uma criticidade tal que nos permita afirmar que as políticas públicas de educação pública no Brasil têm sido pensadas e 
realizadas parcialmente, como convém a uma sociedade desigual econômica, social e culturalmente.

Confirmando tal situação, os dados sobre a educação brasileira evidenciam que:

ainda há cerca de 14 milhões de pessoas analfabetas; as taxas de analfabetismo da área rural são, em média, quase três vezes maiores que as da área urbana; em 2005, a taxa de escolarização líquida de crianças de seis anos era de 62,9\%; a taxa de frequência à escola da população de quatro a seis anos era de $77,6 \%$; a taxa de escolarização das crianças de sete a 14 anos atingiu a quase universalização, com atendimento de 97\%; quanto maior o nível de rendimento familiar per capita, maior a taxa de escolarização de crianças de quatro a seis anos de idade; cerca de $80 \%$ das pessoas de 15 a 17 anos estudam e apenas pouco mais de $30 \%$ dos de 18 a 24 anos, sendo que, destes, $71 \%$ ainda estavam no ensino fundamental ou médio; a defasagem idade-série continua sendo um dos grandes problemas da educação básica; é baixa a média de anos de estudo da população brasileira, que gira em torno de seis anos de escolarização; em 2005, a taxa de escolarização líquida no ensino médio era de 45,3\%. (CONFERÊNCIA NACIONAL DE EDUCAÇÃO, 201 1).

Evidentemente, a desigualdade e a exclusão permanecem. Além disso, os discriminados de ontem continuam a ser os discriminados de hoje. Mas, segundo Oliveira (2007), a desigualdade existente hoje não é mais a mesma e nem ocorre nos mesmos termos da que ocorria no passado. Frações de classe mais pauperizadas reprovam mais, evadem mais, concluem menos, no entanto, mais importante que isso, aprovam mais, permanecem mais e concluem mais do que em qualquer outro momento de nossa história educacional, ainda que permaneçam como os setores mais excluídos.

Ainda segundo o autor, o fato é que, se não se enfatizar o aspecto positivo que a universalização do ensino fundamental representa, não conseguiremos compreender porque os desafios passam a ser outros. Ao se enfatizar a exclusão de sempre, não há elementos para perceber que ela já não é a mesma de duas ou três décadas atrás. 
Por fim, para encaminharmos o fechamento da discussão sobre as perspectivas da escola pública no Brasil, destacamos outra dimensão importante da flexibilização da educação como direito de todos identificada por Frigotto (2005) que diz respeito à "privatização do pensamento pedagógico". Ou seja, a educação, de acordo com Pires e Tozoni-Reis (1999), ocupa um papel estratégico no projeto neoliberal:

de um lado, de preparação para o trabalho, garantia da formação do trabalhador sob nova base técnica: automação e multifuncionalidade. De outro lado, a consolidação da educação, inclusive a escolar, com função ideológica, de transmitir as idéias liberais. Assim o processo educativo incorpora as idéias de organização social oriundas do projeto neoliberal como a competição, o individualismo, a busca da qualidade etc.

Saviani (2007) analisou essa privatização do pensamento pedagógico identificando quatro categorias (provisórias): o neoprodutivismo, o neoescolanovismo, neoconstrutivismo e o neotecnicismo. $\bigcirc$ neoprodutivismo, fundamentado na teoria do capital humano ressignificado, busca organizar o ensino a partir da necessidade de formação humana para as novas formas de produção, flexibilizadas. A formação escolar pretendida, segundo essas análises, refere-se às capacidades e competências, presentes e expressas nos documentos que traçam parâmetros e diretrizes curriculares para a educação básica. Assim, os princípios da Escola Nova, também ressignificados, constituemse como neoescolanovismo, isto é, o "aprender a aprender" que agora também é "formação permanente" dos sujeitos educandos. $\bigcirc$ neoconstrutivismo, expresso particularmente pela teoria do professor que aprende na própria prática, concebe os saberes centrados na experiência cotidiana. A reflexão aqui, cujos fundamentos estão na pedagogia das competências, nos comportamentos flexíveis e na responsabilidade individual, diz respeito à compreensão pragmática da experiência docente. Nesse sentido, resignifica-se também o tecnicismo. Se na década de 1970 seus princípios foram de racionalidade, eficiência e produtividade sob o controle direto do Estado, agora ele aparece sob o controle do mercado, a responsabilidade da iniciativa privada e das 
organizações não governamentais, reduzindo os investimentos públicos por meio das "parceiras público-privadas".

Considerando que os governos que vêm constituindo o Estado têm mantido a escola pública cada vez mais precária, desvalorizando os estudantes da classe trabalhadora ao propor uma educação que serve - servilmente ao mercado, exigindo professores cada vez mais submissos, sem autonomia e precarizados, disponibilizando condições materiais e de infraestrutura cada vez piores e conteúdos cada vez mais superficiais e pragmáticos, é importante entendermos sua organização atual.

A escola pública que temos foi se constituindo historicamente e tem uma configuração hegemônica que intencionalmente busca a formação dos alunos para a adaptação na sociedade e sua reprodução. Frigotto (1999) já discutia como a educação no movimento global, embora não tenha um vínculo direto, articula-se aos interesses capitalistas. Ao debater a produtividade da escola improdutiva, ele demonstrava que a escola pode ser um instrumento eficaz para formular condições concretas superando essas relações sociais, pois, apesar de articulada aos interesses do capital, a escola não é inerente e nem orgânica a esse modo de produção, sendo este um dos aspectos que diferencia a prática educativa escolar.

Com as manifestações dos movimentos estudantis se fortalecendo no País, podemos perceber que, apesar de toda força hegemônica para a manutenção da alienação, os estudantes estão se mobilizando e demonstrando um compromisso político com uma escola pública que possibilite uma formação humanizada, indo na contramão da manutenção de uma escola que serve servilmente ao sistema capitalista.

A desqualificação do trabalho escolar passa por muitas e variadas medidas, mas é uma estratégia necessária ao capital. Tornar o trabalhador do ensino um mero executor de tarefas preconcebidas é o caminho mais esperado. É nesse sentido que a escola - improdutiva - é ao mesmo tempo produtiva para o capital.

A escola será um locus que ocupa - para um trabalho "improdutivo forçado" - cada vez mais gente e em maior tempo e que, embora não produza maisvalia, é 
extremamente necessária ao sistema capitalista monopolista para a realização de mais-valia; e, nesse sentido, ela será um trabalho produtivo. (FRIGOTTO, 1999, p. 27).

Assim, percebemos que, justamente por todo esse potencial de influência e ação na transformação e na reprodução da sociedade que a escola pública foi e ainda é um campo de disputas de projetos de sociedade e um alvo prioritário, principalmente a partir da década de 1990, dos governos do Estado brasileiro que buscaram atender à agenda neoliberal internacional.

Com isso, podemos entender que é a própria função social da escola pública um dos aspectos que está em disputa no capitalismo. A função de formar os educandos para a vida, contribuindo para a formação plena dos seres humanos é subvertida; temos o Estado explorando politicamente a escola pública a favor do capitalismo. Frigotto (1999, p. 151) nos auxilia a refletir sobre a mediação da prática social escolar:

\begin{abstract}
A função da escola, nesse contexto, se insere no âmbito não apenas ideológico do desenvolvimento de condições gerais, da reprodução capitalista, mas também no das condições técnicas, administrativas, políticas, que permitem ao capital "pinçar", na expressão de Gianotti, de dentro dela aqueles que, não pelas mãos, mas pela cabeça, irão cumprir as funções do capital no interior do processo produtivo.
\end{abstract}

A escola pública improdutiva em relação à produção da mais-valia de maneira direta, portanto, atua produtivamente para que a composição e o movimento da produção da mais-valia se concretize, mostrando-se instrumento fundamental para o sistema capitalista. Alguns instrumentos, de acordo com Frigotto (1999), são utilizados para que a escola permaneça sob domínio da burguesia: a desqualificação do trabalho escolar para a maioria, permanecendo aquém inclusive dos interesses econômicos dominantes; a divisão técnica do trabalho escolar, relegando aos professores a tarefa de "aplicação" de atividades e conhecimentos pensados e estabelecidos por outros. 


\section{CONCLUSÃO}

Após essas reflexões, entendemos que é necessário o enfrentamento dessa situação e condição para que se concretize a constituição de uma escola pública, laica, gratuita, obrigatória, de qualidade socialmente referenciada e desinteressada. Ou seja, uma escola que ofereça as ferramentas, por meio do saber sistematizado, a todos, sem distinção e de maneira crítica. Como afirmou Gramsci (apud MANACORDA, 2008, p. 37): "para o proletariado é necessária uma escola desinteressada, uma escola humanística, em suma, como a pretendiam os antigos e os homens mais recentes do renascentismo."

Em diferentes períodos da história, a escola pública foi fortemente criticada por diferentes autores. Entre essas críticas "demolidoras", podemos destacar a noção de Althusser (1974), que compreende a escola como um aparelho ideológico do Estado burguês e, mais do que isso, um instrumento, por excelência, de dominação absoluta do capital. Podemos citar também as abordagens de Illich (1973), considerando a escola uma organização desnecessária, que reproduz a estratificação social, e defendendo, portanto, o seu fim como instituição educacional, já que as pessoas podem aprender e se educar sem ir à escola.

Em oposição a esses referenciais, compartilhamos as reflexões de Gramsci (1978), que vem sendo cada vez mais alvo de estudos aprofundados, tendo em vista a transformação da sociedade. Isso tem contribuído para a formulação de projetos em defesa da educação pública popular.

Para Gramsci, o trabalho dos grupos dominantes para convencer as classes subalternas a aceitar a dominação e a exploração não se realiza apenas no plano intelectual. A veiculação de ideias é acompanhada da proposição de um modo de agir, ficando claro o vínculo dialético entre "teoria" e "prática". Quando a classe dominante consegue dar uma direção intelectual para a sociedade, essa direção também é moral, isto é, implica formas de agir no mundo, a prática social. A hegemonia é o exercício da direção intelectual e moral da sociedade (DORE, 2006). 
Dessa forma, destacamos, com base em Gramsci, a importância de um movimento intelectual que difunda novas concepções de mundo capazes de elevar a consciência civil das massas populares e de produzir novos comportamentos para que elas não se submetam à direção do Estado capitalista.

É desenvolvendo o princípio educativo que Gramsci formula a noção de escola unitária. $\bigcirc$ "princípio unitário" ultrapassa a escola como instituição (GRAMSCI, 1977 apud DORE, 2006, p. 339) e se relaciona à luta pela igualdade social, para superar as divisões de classe, que se expressam na separação entre trabalho industrial e trabalho intelectual e dividem a sociedade entre governantes e governados.

A escola unitária tem como ponto de partida as relações sociais dentro do capitalismo, já que Gramsci não fala em destruir o capitalismo primeiro e somente depois disso cuidar da educação dos trabalhadores. Ele não tem uma visão dicotômica da relação entre Estado e sociedade. A escola unitária está no horizonte de um processo de construção que, por ser dialético, é simultaneamente de destruição (DORE, 2006).

Portanto, a alternativa de Gramsci, que consideramos ser a que pode responder mais às questões que discutimos até então, é a escola desinteressada, a escola única:

a crise terá uma solução que, racionalmente, deveria seguir esta linha: escola única inicial de cultura geral, humanística, formativa, que equilibre de modo justo o desenvolvimento da capacidade de trabalhar manualmente (tecnicamente, industrialmente) e o desenvolvimento das capacidades de trabalho intelectual. Deste tipo de escola única, através de repetidas experiências de orientação profissional, passarse-á a uma das escolas especializadas ou ao trabalho produtivo. (GRAMSCI, 201 1, p. 33-34).

Pudemos perceber, por meio da história da escola pública, que seus desafios ainda são complexos e que sua necessidade permanece urgente. Com isso, compreendemos e defendemos uma educação pública de qualidade socialmente referenciada por meio de uma escola pública popular, que represente as necessidades da maioria da população, tendo em vista o 
necessário processo de humanização que o ato educativo proporciona no desenvolvimento do ser humano. Para isso, o enfrentamento dessa condição extremamente desigual da educação pública brasileira precisa acontecer, considerando a luta pelos interesses da educação da classe trabalhadora.

\section{REFERÊNCIAS}

ALTHUSSER, L. Ideologia e aparelhos ideológicos do Estado. Lisboa: Presença, 1974.

ALVES, G. L. A produção da escola pública contemporânea. Campinas: Autores Associados; Campo Grande: Ed. UFMS, 2004.

BOTO, C. A educação escolar como direito humano de três gerações: identidades e universalismos. Educação e Sociedade, Campinas, v. 26, n. 92, p. 777-798, out. 2005. Edição especial.

CHAUI, M. A universidade pública sob nova perspectiva. Conferência de abertura da 26ª Reunião Anual da ANPED. Poços de Caldas, MG, 05 de outubro de 2003. Revista Brasileira de Educação, n. 24, p. 5-15, 2003.

\section{CONFEREANCIA NACIONAL DE EDUCAÇÃO. Anais da Conferência Nacio-} nal de Educação: Construindo o Sistema Nacional Articulado de Educação: o Plano Nacional de Educação, diretrizes e estratégias de ação. Brasília, DF: MEC, 2011.

DORE, R. Gramsci e o debate sobre a escola pública no Brasil. Cadernos Cedes, Campinas, v. 26, n. 70, p. 329-352, set./dez. 2006.

ENGUITA, M. A face oculta da escola. Porto Alegre: Artes Médicas, 1989.

FRIGOTTO, G. A produtividade da escola improdutiva: um (re)exame das relações entre educação e estrutura econômico-social e capitalista. 5. ed. São Paulo: Cortez, 1999.

FRIGOTTO, G. A qualidade da educação escolar no Brasil: um contraponto à concepção hegemônica. In: BERTUSSI, G.T.; OURIQUES, N. (Org.). Anuuário Educativo Brasileiro: visão retrospectiva. São Paulo: Cortez, 2011.

FRIGOTTO, G. Escola pública brasileira na atualidade: lições da história. In: LOMBARDI, J.C; SAVIANI, D; NASCIMENTO, M.I.M. A escola pública no

Brasil: história e historiografia. Campinas: Autores Associados, 2005. 
GRAMSCI, A. Caderno 12 (1932): apontamentos e notas dispersas para um grupo de ensaios sobre a história dos intelectuais. In: GRAMSCI, A. (Org.). Cadernos do Cárcere: os intelectuais. $\bigcirc$ princípio educativo. Jornalismo. 6. ed. Rio de Janeiro: Civilização Brasileira, 201 1. v. 2.

GRAMSCI, A. Os intelectuais e a organização da cultura. Rio de Janeiro: Civilização Brasileira, 1978.

ILLICH, I. Sociedade sem escolas. Petrópolis: Vozes, 1970.

LEONEL, Z. Contribuição à história da escola pública: elementos para a crítica de teoria liberal da educação. Tese (Doutorado em Educação)-Faculdade de Educação Unicamp, Campinas, 1994.

LOMBARDI, J. C.; SAVIANI, D.; NASCIMENTO, M. I. M. A escola pública no Brasil: história e historiografia. Campinas: Autores Associados, 2005.

LOPES, E. M. S. T. Origens da educação pública: a instrução na Revolução Burguesa do Século XVIII. 1. ed. São Paulo: Fino Traço Editora, 2008.

MANACORDA, M. A. O princípio educativo em Gramsci. Americanismo e conformismo. Campinas: Alínea, 2008.

MARX, K. Grundrisse. São Paulo: Boitempo; Rio de Janeiro: Ed. UFRJ, 2011.

OLIVEIRA, R. P. Da universalização do ensino fundamental ao desafio da qualidade: uma análise histórica. Educação e Sociedade, Campinas, v. 28, n. 100, p. 661-690, out. 2007. Edição especial.

PIRES, M. F. C.; TOZONI-REIS, J. R. Globalização, Neoliberalismo e Universidade: algumas considerações. Interface - Comunicação, Saúde, Educcação, n. 4, p. 29-39, 1999.

RIBEIRO, M. L. S. Educação Escolar: que prática é essa? Campinas: Autores Associados, 2001.

SANFELICE, J. L. Da escola estatal burguesa à escola democrática e popular: considerações historiográficas. In: LOMBARDI, J. C.; SAVIANI, D.; NASCIMENTO, M. I. M. (Org.). A escola pública no Brasil: história e historiografia. Campinas: Autores Associados, 2005.

SAVIANI, D. Escola e democracia. 40. ed. Campinas: Autores Associados, 2008. 
SAVIANI, D. História da escola pública no Brasil: questões para pesquisa. In: LOMBARDI, J. C.; SAVIANI, D.; NASCIMENTO, M. I. M. (Org.). A escola pública no Brasil: história e historiografia. Campinas: Autores Associados, 2005.

SAVIANI, D. História das ideias pedagógicas no Brasil. Campinas: Autores Associados, 2007

SOUZA, P. R.; FERREIRA, M. M. D. M.; BARROS, M. S. F. História da criação da escola pública como instrumento da formação da educação burguesa. In: CONGRESSO NACIONAL DE EDUCAÇÃO (EDUCERE), 9., 2009, Curitiba. Anais... Curitiba: Pontifícia Universidade Católica do Paraná, 2009.

TOZONI-REIS, M. F. C. Políticas públicas para a educação no Brasil: contribuições para compreender a inserção da educação ambiental na escola pública. In: CRUZ, L. G.; TOZONI-REIS, M. F. C; SPAZZIANI, M. L. (Org.). Ass políticas de educação ambiental e sua inserção na escola pública. XVI ENDIPE Encontro Nacional de Didática e Práticas Pedagógicas. Campinas: 2012 .

Recebido em 08 de dezembro de 2017 Aceito em 12 de junho de 2018

Endereços para correspondência: Avenida Brasil, 679, Centro, 79740-000, Ivinhema, Campo Grande, Mato Grosso do Sul, Brasil; lilian.giacomini@ gmail.com 
